\title{
Lecture Material Retention: a First Trial Report on Flipped Classroom Strategies in Electronic Systems Engineering at the University of Regina
}

\author{
Doug Wagner ${ }^{[a]}$, Paul Laforge ${ }^{[a]}$, Douglas Cripps ${ }^{[b]}$ \\ ${ }^{[a]}$ Electronic Systems Engineering, Faculty of Engineering \& Applied Science, University of Regina \\ ${ }^{[b]}$ Center for Teaching and Learning, University of Regina \\ Douglas.Wagner@uregina.ca Paul.Laforge@uregina.ca Doug.Cripps@uregina.ca
}

\begin{abstract}
There is increasing pressure to incorporate aspects of the online education model into Canadian Universities. There is also a valid criticism of traditional engineering education models based on the conventional classroom lecture.

Whether lectures are seen as boring or extremely entertaining, maximizing student comprehension and engagement as well as retention of information presented in conventional lectures is a challenge being faced widely in engineering education. The strategy explored in this paper is the use of a flipped lecture component in Electronic Systems Engineering courses at the University of Regina.

With assistance from the University of Regina's Center for Teaching and Learning, the application of a flipped lecture technique was trialed in a Winter 2013 ESE Course. The results, and future plans are presented.
\end{abstract}

Keywords: Flipped Lecture: Lecture Retention: On Line Lectures: YouTube: Camtasia

\section{INTRODUCTION}

Retention of lecture material by engineering students is a challenging aspect of higher education. The classical method of engineering concept reinforcement used in the University of Regina ( $U$ of R) Electronic Systems Engineering (ESE) program is a combination of laboratory experiences and course project work supporting traditional lectures. Given the current equipment, time and space challenges faced by many post-secondary institutions it is difficult to match every concept presented in lecture with a corresponding lab or project. The effectiveness of lab reinforced materials in comparison to lecture delivered materials has become apparent in the analysis of Outcomes Based Assessment indicators captured from a fifth semester electrical design class, where the design outcomes measured in the lab and final exam are compared (see Figure 1).

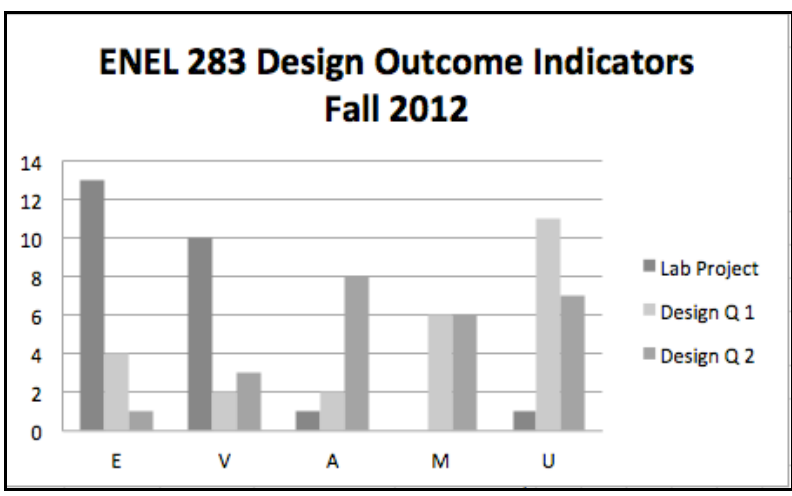

Figure 1. Assessment Indicators, ENEL 283 Fall 2012

Design Attribute

$(E=E x c e l l e n t, V=$ Very Good, $A=$ Average, $M=$ Marginal, $U=$ Unacceptable)

Figure 1 highlights that lab reinforced materials show a much stronger scoring in the measured attributes when compared to equivalent design problems given in an examination.

The issue of lecture-based learning, which has long been a concern, was again raised recently in the media in the fall of 2012. Ira Basen entertainingly summarized issues of traditional lectures on CBC Radio's Sunday Edition in September 2012. ${ }^{[1]}$ The radio documentary's focus was on the contrast in effectiveness between "Massive Online Open Courseware" (MOOC's) ${ }^{[2]}$ as opposed to "Massively Outdated Traditional Education" (MOTE's) ${ }^{[3]}$ in terms of material delivery.

The assessment of outcomes indicators, coupled with awareness in part generated by the media led to the assumption that the delivery vehicle itself may be part of the challenge faced in attempts to increase the effectiveness of technical content uptake on the part of our students.

A number of engineering faculty collaborated with the $\mathrm{U}$ of R Center for Teaching and Learning (CTL) to assist in the identification of a strategy to improve our teaching 
effectiveness within the constraints of our resources. The team ultimately decided to explore flipped lectures as a tool to enhance the presentation and retention of lecture material.

This paper presents the model that was trialed in the Winter 2013 semester in a final semester engineering course that previously relied only on traditional lecture and lab components. Student feedback was gathered through an anonymous survey at the end of the course, and qualitatively through the semester. The consensus is that flipped lectures are a valuable tool for enhancing engineering material delivery in the Electronic Systems Engineering program at the $\mathrm{U}$ of $\mathrm{R}$.

\section{FLIPPED LECTURE MODEL}

The flipped lecture model used in the $\mathrm{U}$ of $\mathrm{R}$ pilot was straightforward: take a percentage of the lectures allocated in a given course, and deliver the lecture material for those courses via some form of media prior to the lecture, then utilize that lecture time for in-class course work based on that lecture.

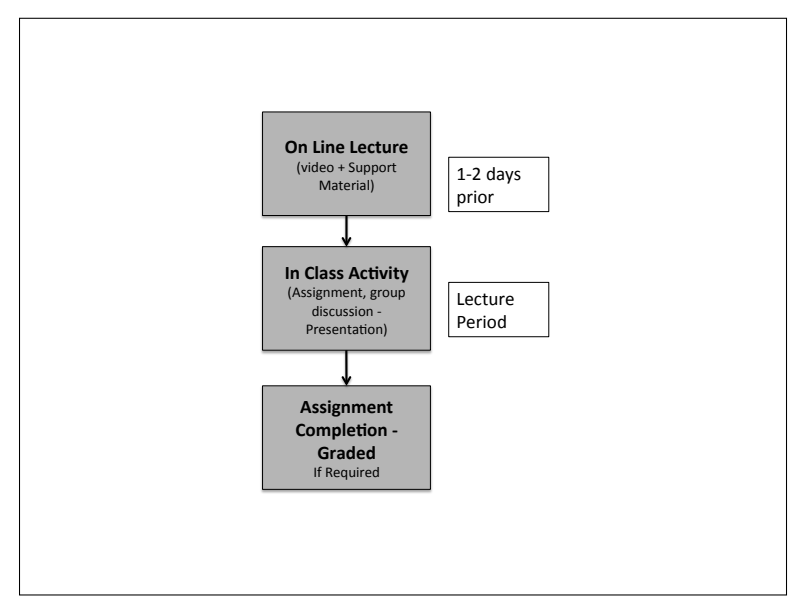

Figure 2. Flipped Lecture Model.

The decision to implement a trial flipped lecture was taken after consultations January 3, 2013 for a semester commencing January 7,2013 . The short turn-around from decision to implementation meant there was very little time to explore other flipped lectures, such as presented by Ronchetti ${ }^{[4]}$, however these resources have been useful to consult to see how closely the $U$ of $R$ trial tracked with other advocates of this instructional strategy.

The initial goal was to deliver one flipped lectureassignment component per week in the course, amounting to 12 flipped lectures over the course of the semester. This target was not achieved, given that two industry guest lectures were scheduled and in-class time was allocated for examinations and course projects. A total of six formal flipped lectures were designed and presented, with two additional informal on line components included as part of the course content (one review and the other providing supporting background materials). Given the student's familiarity with course materials coming via an online source, the same vehicle was also used for lab background presentation, mid term examination results and final examination review.

Each flipped lecture component consisted of a video lecture, supporting materials (lecture slides presented in the video for enhanced resolution and reference) and a specific in class assignment.

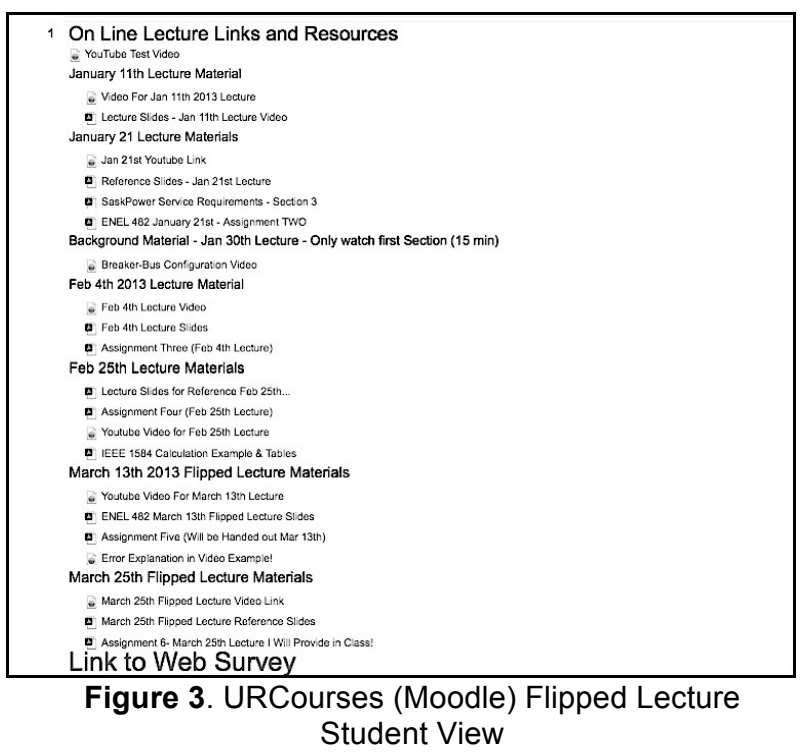

The video materials were authored using Camtasia $2^{[5]}$ for Mac, and delivered via YouTube ${ }^{[6]}$ as unlisted videos.

\subsection{Online Course Work}

The key to gaining benefit from the flipped lecture concept is to use the time normally devoted to covering course material in class to instead work on a strategically designed instructor-supported assignment. Several styles of in-class activities were explored during this trial, with varying degrees of success.

- Assignment 1 - Group activity, with teams of 4 students engaged in a group calculation of utility costs based on different configurations of transformer voltage and ownership.

- Assignment 2 - Group and individual take home component, using class time for clarification and discussion, dealing with quantification and classification of power systems harmonics relative to utility specification, 
- Assignment 3 - Individual in-class assignment to develop grounding and bonding specification,

- Assignment 4- Group and individual assignment dealing with arc flash mitigation strategies. In-class activity involved teams presenting the theory of operation and advantages of one particular type of arc flash reduction technique - individual component involved quantitative implementation of one particular technique,

- Assignment 5 - Individual assignment in class and out of class completion of a peak shaving case study,

- Assignment 6 - Individual assignment in class and out of class completion of a power quality improvement case study.

\subsection{Evaluation of Flipped Lectures by Students}

An extensive anonymous survey was conducted at the end of the ENEL 482 Power Systems course to garner student feedback. Over 40 questions were asked on a per-lecture and assignment basis. The class size was 18 students, which included 9 masters of engineering graduate students and 9 undergraduate engineering students. There was a $100 \%$ completion rate of the overall survey, however some individual questions were skipped by participants. Some of the results are presented in summary:

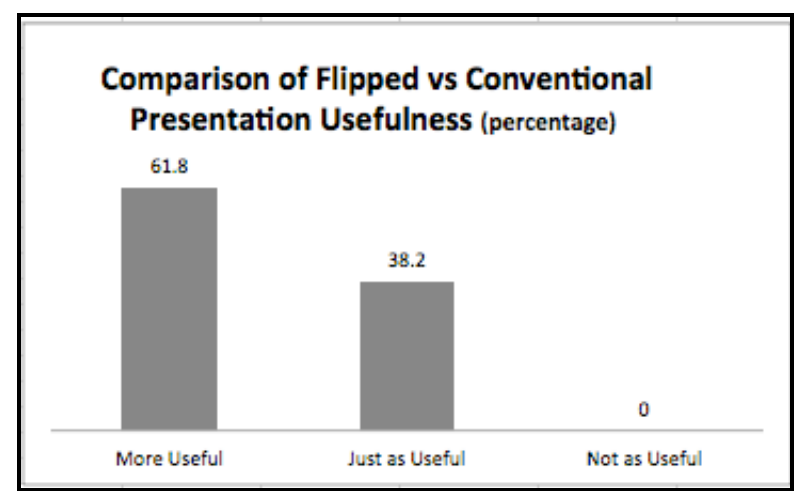

Figure 4. Comparison of Flipped vs. Conventional presentation of material in the online lectures

All respondents found the flipped lecture approach as effective as traditional lectures - and in many cases more useful than a conventional lecture. Further, the majority of respondents indicated the strategically designed inclass assignments were a better use of class time (see Figure 5).

\section{Comparison of Class and Assignment Time (percentage)}

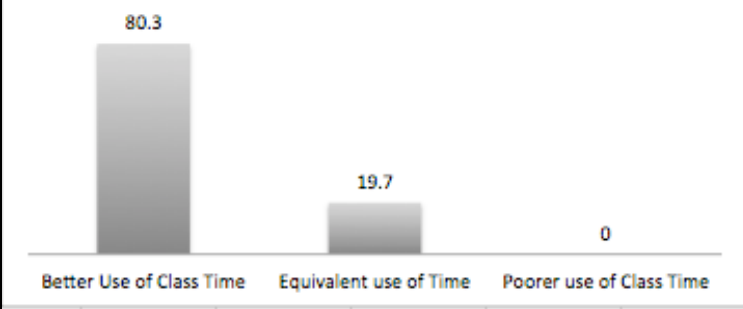

Figure 5. Best use of Time Comparison

One key issue in the delivery of lecture materials via video was the length of video presentation. In this project, online lecture videos varied from 6 to 30 minutes in length. Qualitatively students raised many concerns if the length of the video exceeded 20 minutes. Survey results are shown in Figure 6 and suggest the majority of students (nearly 60\%) prefer videos between 10 and 15 minutes long with another $35 \%$ suggesting that less than 10 minutes is the preferred length.

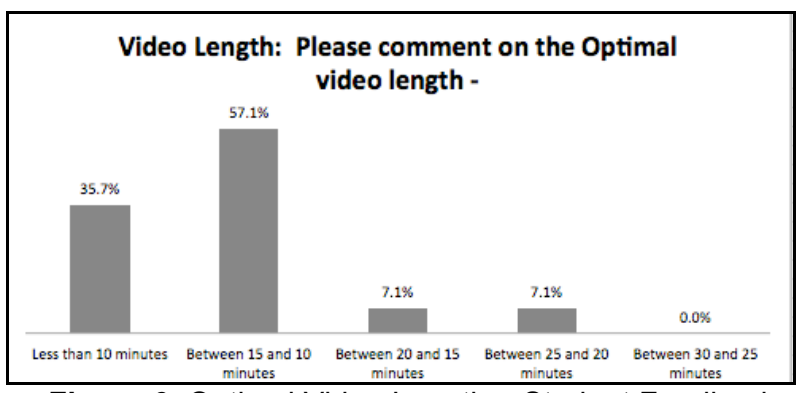

Figure 6. Optimal Video Length - Student Feedback

Figure 7 reveals that over $90 \%$ of students felt that flipped lectures are a valuable tool in the presentation of engineering material.

\section{General Concept of Flipped Lectures: Do you feel that Flipped lectures are a valuable tool in the presentation of Engineering material?}

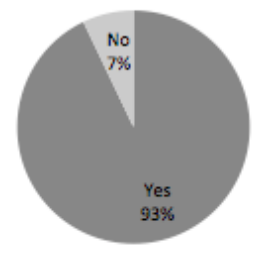

Figure 7. Overall Response - Flipped Lecture Trial 


\section{CONCLUSION}

The trial of flipped lectures in ENEL 482 at the University of Regina in the 2013 winter semester was deemed successful by the students exposed to the novel teaching strategy and by the faculty involved. The feedback gleaned through student survey, both interactively throughout the semester, and at the end of the course yielded a number of suggestions for future implementation:

- $\quad$ The success of flipped lectures is directly tied to the nature of the in-class assignment. Poorly designed assignments that rely solely on group interaction typically result in stronger students carrying less engaged students. Individual assignments, with group interaction appear to have the most educational benefit.

- While ideally the in-class assignment would be designed to allow for completion during the lecture time, on average meaningful assignments required the students to complete the assignments on their own time.

- Video length, and quality is important to student engagement in the material. The timeliness of video availability is also important. During the trial, videos were typically available less than 24 hours prior to lecture. Ideally, the online lecture materials should be available immediately after the preceding lecture.

- Video lectures provide an ongoing resource to students after the targeted lecture. On average, the flipped lecture videos have been viewed 3 times per student over the course of the semester. Our results suggest that videos covering content early in the semester have been viewed more often, on average, than videos which covered content from later in the semester. This may prove to be a valuable study aid for students preparing for a comprehensive final examination.

- Students are very aware of the potential for a class to exceed its credit-hour load if online lectures are used excessively. It is incumbent upon the course instructor to ensure that workload is balanced for the students, and not excessively increased.
- Student's opinion was that a 30\% flipped lecture component represents the optimum saturation level for this educational tool based on their experience in this course. This translates into one flipped lecture per week.

- Initial video production represents a significant added workload to the course instructor. On average a 15-minute online lecture required 2 to 3 hours of production and editing time using extremely user-friendly development tools. This investment can be recaptured once defined video lectures are produced, and used from year to year. Production time is not necessarily geared to achieving a "perfect lecture" but instead to ensure that the lecture online is as engaging as possible for the students.

- Adopting the flipped lecture instructional strategy can assist in more effective use of class time. For example, two additional lectures and a portion of office hour time were gained back by providing online review and exam explanation materials to the students by using the online video recording.

This study has resulted in a degree of excitement by those involved with the initial trial of flipped lectures in the engineering faculty at the $U$ of $R$. Any tool that can further teaching effectiveness is a positive development. Further, online delivery of content provides for the possibility of future expansion into professional development and fully online course delivery.

Flipped lecture materials also offer a unique, yet challenging opportunity for universities to collaborate on maximizing the effectiveness of engineering education. The model of the Khan academy ${ }^{[7]}$ and MIT Open Courseware $^{[8]}$ may allow universities to effectively bring in a guest lecturer on a topic, to the benefit of the students, thereby enhancing the overall impact of the course in which it is included.

For further information, including access to the on line lectures, companion assignments, and student survey please contact Doug Wagner, P.Eng at Douglas.Wagner@uregina.ca 


\title{
4. REFERENCES
}

1 Ira Basen "Universities in the Digital Age", The Sunday Edition, CBC Radio One, Airdate September 9, 2012.

2 Massively Outdated Traditional Education (MOTEs). Accessed online http://hastac.org/blogs/cathydavidson/2012/07/20/lets-talk-about-mooc-onlineeducation-and-also-about-massively-outda, January 2013.

3 Ibid.

\author{
4 Ronchetti, Marco. "Using video lectures to make teaching \\ more interactive" International Journal of Emerging \\ Technologies in Learning (iJET) [Online], 52 Jun 2010 \\ ${ }^{5}$ Camtasia 2 Version 2.3.0 (77283), Copyright (2006-2012) \\ Techsmith Corporation \\ ${ }^{6}$ www.YouTube.com \\ ${ }^{7}$ https://www.khanacademy.org/ \\ 8 http://ocw.mit.edu/index.htm
}

